CASE NOTES

\title{
CONGENITAL ABSENCE OF INFERIOR RECTUS AND EXTERNAL RECTUS MUSCLES*
}

BY

\author{
J. P. SPENCER WALKER \\ Sussex Eye Hospital, Brighton, and Horsham Hospital
}

THE absence of one of the extrinsic muscles of the eye is sufficiently rare to encourage me to report the following two cases. In the first, there was a complete absence of the inferior rectus and in the second, of the external rectus. Spaeth (1948) says that congenital absence of the obliques was reported by Harles (1880) and that absence of the superior and inferior recti is more common. Absence of the external rectus would appear to be rarer still.

\section{Case Reports}

Case 1, a man, aged 35, consulted me because his appearance was such that his life was miserable. There was gross hypertropia of the left eye, and he also had a convergent strabismus of about $40^{\circ}$. It was decided to deal with the hypertropia first. On August 6, 1952 , I recessed the left superior rectus, and as this had little or no effect I thought $I$ should advance or resect the inferior rectus. At a second operation on August 13 I found that the inferior rectus was completely absent. As there was such a marked esotropia, I decided that he could well afford to lose the lower third of the internal rectus, and therefore transplanted this portion, stitching it into the position of insertion of the absent inferior rectus. This operation was completely successful in bringing the left eye down level with the right, and it was obvious that a pleasing result could be obtained by further operation. This had to be postponed till the following May, when a recession of the remaining two-thirds of the internal rectus and a resection of the external rectus gave an excellent result. The patient is now a changed man and delighted with the improvement in his appearance.

Case 2, a child, aged 1 year 11 months, had a marked esotropia of the right eye. She appeared to be unable to fix with it, and the angle of deviation was estimated to be about $45^{\circ}$. No movement outwards beyond the mid-line was elicited with either eye. I decided that this was a case for early operation, and on September 30, 1953 I recessed both internal recti. The child was observed for a few weeks, and it became apparent that a further operation would be necessary. On December 15 I found that there was no movement of the right eye outwards beyond the mid-line, but the left eye moved fully outwards. At operation on December 16, there was a complete absence of the right external rectus, though the insertions of the two obliques could be clearly seen.

It is obvious that something must be done to improve the child's appearance. Possible treatment is to transplant the outer third of the superior and inferior recti to form a new external rectus, a procedure similar to that which is often carried out in palsy of the external rectus. I have found in these latter cases that the initial good result is often functionally disappointing after the lapse of time, presumably through fibrosis of the muscle tissue.

\section{REFERENCES}

Spaeth, E. B. (1948). " "Principles and Practice of Ophthalmic Surgery", 4th ed., p. 283. Kimpton, London; Lea and Febiger, Philadelphia.

*Received for publication February 5, 1954. 